\title{
A case of 'low tension glaucoma' with primary empty sella
}

\author{
SHIGEKI YAMABAYASHI, TETSUYA YAMAMOTO, TAKAYA SASAKI, \\ AND SHIGEO TSUKAHARA
}

From the Department of Ophthalmology, Yamanashi Medical College, Tamaho, Yamanashi 409-38, Japan

SUMmARY A case of 'low tension glaucoma' with primary empty sella is reported. The visual field defect and optic disc change were characteristic of glaucoma. The intraocular pressure was within normal limits. $X$-ray examination and the metrizamide-CF procedures revealed a primary empty sella. The coexistence of 'low tension glaucoma' and empty sella is discussed.

The term 'empty sella' was introduced by Busch' and applied to the appearance of the sella turcica in which the diaphragma sellae is incomplete and the pituitary gland appears to be absent anatomically. It is divided into two categories - primary (without prior surgical or radiotherapeutic procedures) and secondary (following such procedures). ${ }^{2}$ The latter type is reported to show a variety of visual disturbances. ${ }^{34}$ On the other hand the former type is associated with few ophthalmological dysfunctions. ${ }^{56}$

We report a patient with glaucoma-like optic disc changes and visual field defects coexisting with the primary empty sella syndrome. And we also draw attention to the need for neurological examinations when we encounter 'low-tension glaucoma'.

\section{Case report}

A 70-year-old woman (height $149 \mathrm{~cm}$, weight $44.6 \mathrm{~kg}$ ) was referred to us in February 1986 by her family doctor. She had no history of radiotherapy, intracranial operations, hypertension, or diabetes mellitus, but she had had mild bifrontal headaches from before the age of 10 years. Her menstrual periods occurred from age 14 to 44 years, but were sometimes irregular, with abnormally large haemorrhages occasionally. Her two daughters gave no history of glaucoma, optic nerve disease, or intracranial disease. Her other relatives were likewise healthy.

The patient's corrected visual acuities were 1.0 in

Correspondence to Shigeki Yamabayashi, MD, Department of Ophthalmology, Yamanashi Medical College, Tamaho, Yamanashi 409-38, Japan the right eye and 0.8 in the left. Her eye movements were normal in all directions. The pupils were round and of equal size. Direct and indirect light reflexes were brisk, and the swinging flashlight test gave normal results. The anterior segments of both eyes were normal on slit-lamp examination except for incipient cataract (anterior and posterior subcapsular). The right optic disc showed glaucomatous excavation, with a C/D ratio $95 \%$, and the left disc had glaucomatous excavation, with a C/D ratio $85 \%$. The superior and inferior rims were narrower than the temporal and nasal rims. The lamina cribrosa was clearly visible in both eyes (Fig. 1). Applanation tension was RE, $14 \mathrm{mmHg}, \mathrm{LE}, 16 \mathrm{mmHg}$. The facility of outflow was $0.24 \mu \mathrm{l} / \mathrm{min} / \mathrm{mmHg} \mathrm{RE}$ and $0.30 \mathrm{LE}$. Gonioscopically the chamber angles were wide open in both eyes. Perimetry with Goldmann and Humphrey perimeters showed a nasal upper visual field defect in the left eye and a nasal upper quadrant defect in the right eye (Fig. 2). A 100-hue colour test showed error scores of 45 , and the pattern electroretinogram (ERG) showed a good response. The diurnal profile (every two hours) of intraocular pressure ranged from 12 to $16 \mathrm{mmHg}$ in the right eye and from 13 to $17 \mathrm{mmHg}$ in the left eye (Fig. 3). Central critical flicker value showed $45-50$ cycle/s in both eyes.

$X$-ray examination of the skull showed an oval configuration and increased volume of the sella turcica (Fig. 4). The length of the sella turcica was 17 $\mathrm{mm}$, the depth $15 \mathrm{~mm}$, the width $22 \mathrm{~mm}$, and the volume $2187 \mathrm{~mm}^{3}$. The lumbar cerebrospinal fluid gave a pressure $120 \mathrm{~mm} \mathrm{H}_{2} \mathrm{O}$ opening pressure. The fluid contained no cells and the concentration of protein was normal. By metrizamide computed 

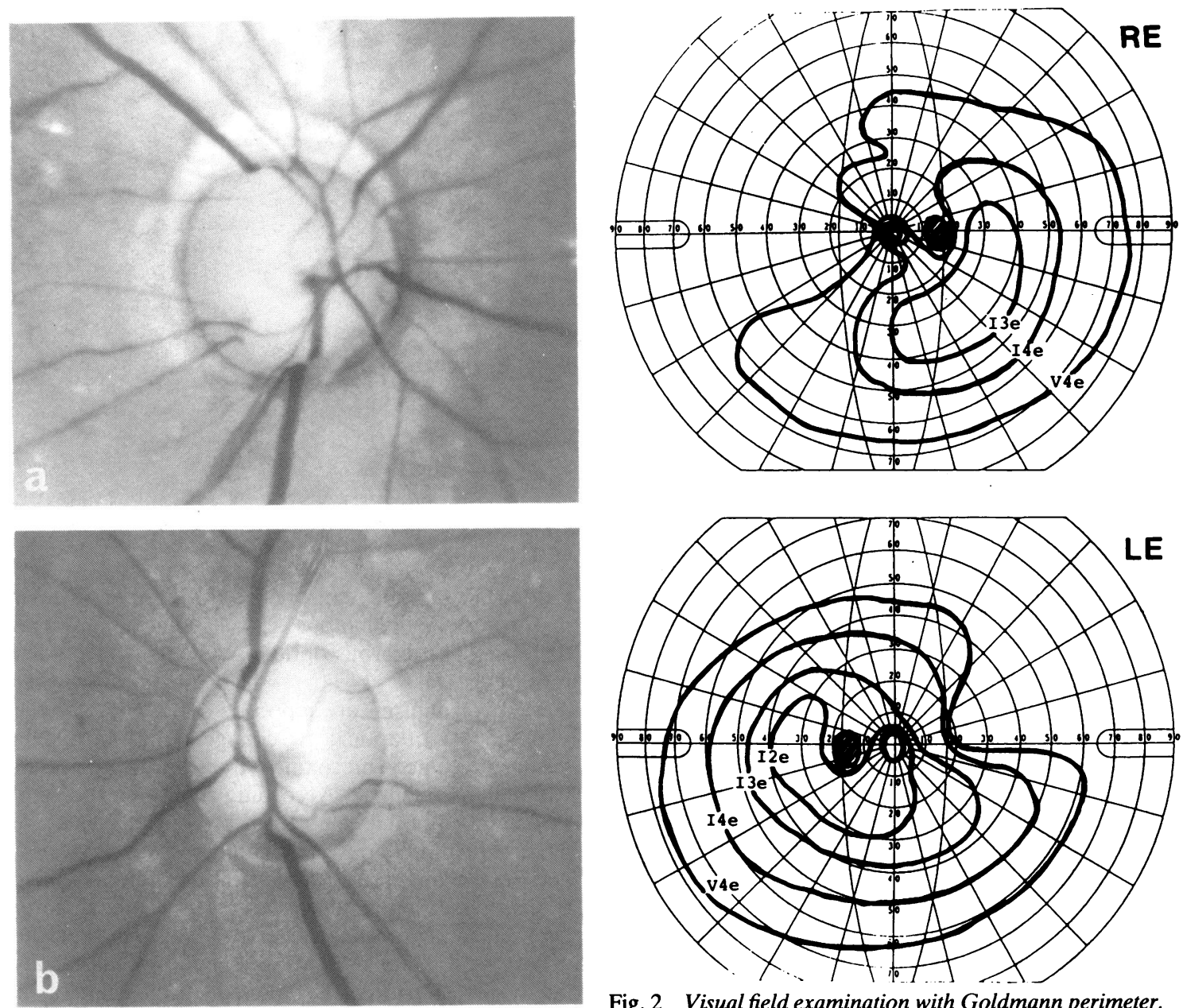

Fig. 1 Fundi of both eyes. Note typical glaucomatous cupping. These photographs were taken with a green filter. a: Disc of right eye. $C / D=95 \%$. b: Disc of left eye. $C / D=85 \%$.

tomography (CT) the sella turcica showed high density absorption (Fig. 5).

The patient was followed up without any treatment for one year. There was no progression of the optic disc changes or visual field defects.

\section{Discussion}

Some differences of opinion exist on the criteria for the diagnosis of low tension glaucoma. Our diagnostic criteria for low tension glaucoma are as follows: (1) the presence of glaucomatous changes in the optic disc and visual field; (2) normal IOP, which means that the diurnal curve of the IOP never exceeds $21 \mathrm{mmHg}$; and (3) no systemic or ocular disease causing the optic nerve changes. Our case raises the question of low tension glaucoma or

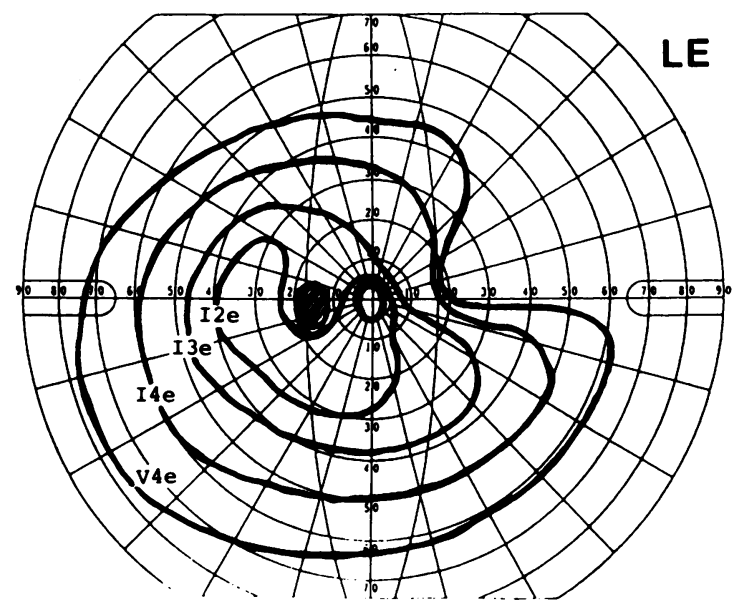

Fig. 2 Visual field examination with Goldmann perimeter. Note the defect in both upper nasal quadrants.

pseudoglaucoma. The coexistence of an empty sella with a glaucomatous optic disc and visual field changes without a high IOP is discussed below.

Most cases of primary empty sella do not show conspicuous disturbances of the visual field, but there have been a few cases with glaucoma-like field defects. Berke ${ }^{5}$ reported two cases with a visual field defect among 19 cases of primary empty sella; one case had a right homonymous hemianopsia and the other case had a right temporal upper defect. These cases showed no glaucomatous changes in the discs. Okamoto and associates ${ }^{7}$ reported a case with unilateral central scotoma as is seen in retrobulbar neuritis. ${ }^{7}$ Nakajyo and associates ${ }^{\sharp}$ reported a case with bitemporal upper quadrant field defect, but there was no abnormality of the disc. On the other hand Neelon et al. ${ }^{4}$ reported a case with a slight defect in the periphery of both nasal and temporal superior fields from 31 primary cases of empty sella, which his 


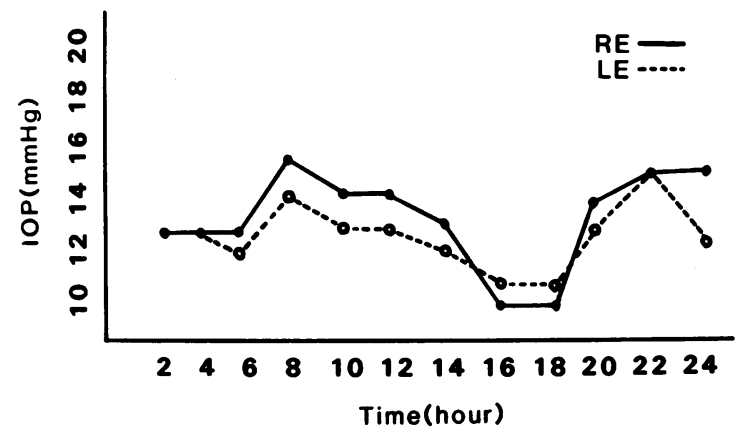

Fig. 3 Daily profile of intraocular pressure which was checked every 2 hours.

consulting perimetrist thought to be probably within the normal range. Shinoda and associates ${ }^{9}$ reported two cases with nasal defects; one case showed slight temporal pallor of discs and the other case showed moderate concentric disc cuppings, but there were no ophthalmological changes diagnostic of glaucoma.

On the other hand the secondary empty sella differs in its symptomatology from the primary empty sella syndrome. Jordan et al.$^{10}$ reported three cases of secondary empty sella with visual field defects. The first case showed a bitemporal defect, the second a right temporal defect, and the third a left temporal and right central scotoma. ${ }^{10}$ Shinoda et al. ${ }^{9}$ described an enlargement of the Mariotte blind spot and both choked discs in a case of the secondary type following meningitis. According to previous reports the defects

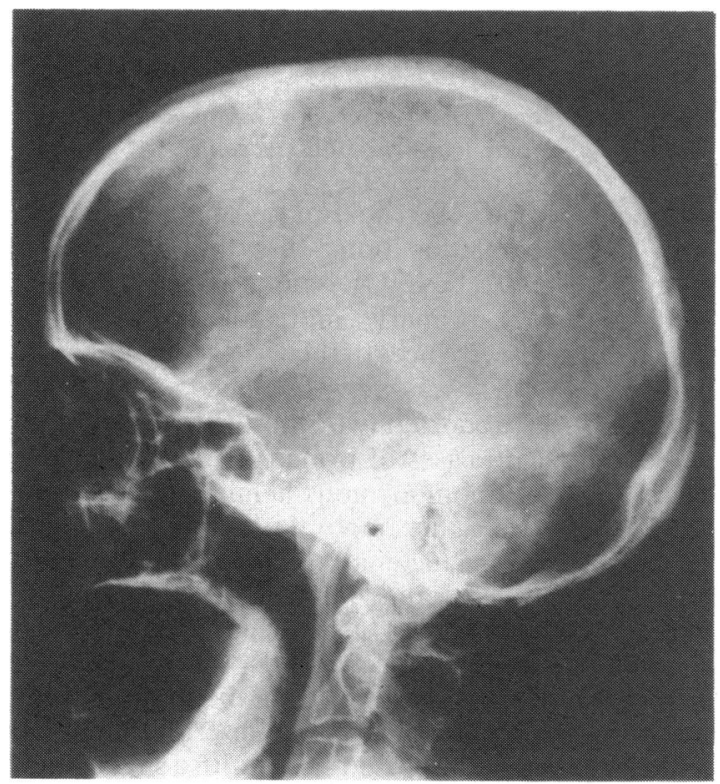

Fig. 4 Lateral view of plain radiograph of the skull. Note ballooning of the sella turcica.

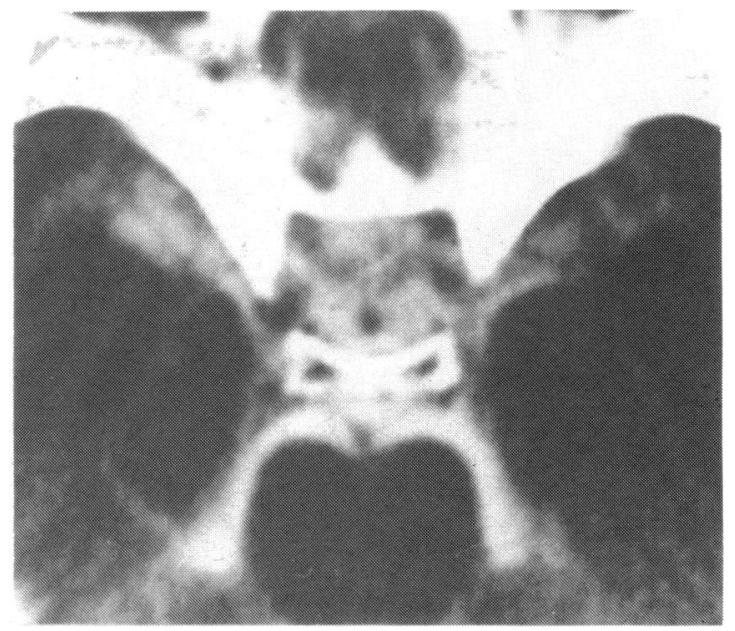

Fig. 5 Metrizamide-CT shows high absorption into sella turcica.

tend to occur in the temporal field. Moreover, even if it showed glaucomatous visual field defects, no definite glaucomatous optic disc changes have been reported so far.

Two mechanisms are supposed to be related to the pathogenesis of optic nerve change in the empty sella syndrome. One is mechanical traction and the other vascular ischaemia. According to Bergrand and associates $^{11}$ the nerve fibres in the optic chiasm are perfused from the posterior communicating arteries, and these arteries pass round the infundibulum above the pituitary gland and also perfuse this area. Therefore, if some mechanical changes occur near the pituitary or the sella turcica, firstly the arachnoid may be drawn inferiorly and the optic chiasm may be pulled downward at the same time; secondly, these perfusion vessels are also retracted, with resultant ischemic changes in the optic nerve. Okamoto et al. ${ }^{7}$ mentioned about the arachnoiditis of the optic chiasm as another factor which produces field loss. In their view loss of visual field is usually caused by vascular strangulation. Meanwhile, postoperative adhesion and postirradiation vasculitis may cause delayed atrophy of the optic nerve and chiasm in secondary empty sella syndrome. ${ }^{3}$

Neurological diseases affecting the optic nerve or chiasm should always be considered before making a definite diagnosis of low tension glaucoma, since they may produce visual field defects that can be confused with glaucomatous changes. In the present case a nasal field defect and glaucomatous disc changes were observed. A question remains whether these changes are related to glaucoma or to the empty sella. There are two possible explanations, one is that the two diseases occurred independently by chance that is, the diagnosis is low tension glaucoma - and 
the other is that the two diseases are related to each other - that is, the diagnosis is pseudoglaucoma. If the latter is true, this case may explain the pathogenesis of at least some cases of glaucomatous optic atrophy.

Pneumoencephalography has been used to diagnose the empty sella syndrome, but this procedure may have some complications. In the present case metrizamide-CT was used to define the empty sella. This agent is a radiopaque derivative from a benzamido and a glucopyranose and very soluble in water. The procedure is simpler than pneumoencephalography and side effects are less common..$^{912}$

This case suggested to us that a complete examination for intracranial diseases is necessary in case of low tension glaucoma. The clinical diagnosis of empty sella is thought to be very difficult by plain radiography and some cases need to be examined by metrizamide-CT. Therefore, if we can apply this procedure in all cases of low tension glaucoma, more cases of empty sella will be found.

\section{References}

1 Busch W. Die morphologie der Sella turcica und ihre Berzichugen zur Hypophyse. Virchows Arch (A) 1951; 320: 437-58.
2 Weiss SR, Raskind R. Non-neoplastic intrasellar cysts. Int Surg 1969; 51: 282-6.

3 Lee WM, Adams JE. The empty sella syndrome. J Neurosurg 1967; 28: 351-6.

4 Neelon FA, Goree JA, Lebovitz HE. The primary empty sella: clinical and radiographic characteristics and endocrine function. Medicine 1973; 52: 73-92.

5 Berke JP, Buxton LF, Kokmen E. The 'empty' sella. Neurology $1975 ; 25: 1137-43$.

6 Bernasconi V, Giovanelli MA, Papo I. Primary empty sella. J Neurosurg 1972; 36: 157-60.

7 Okamoto S, Matsuzaki H, Kitahara H, Irie J, Wakamatsu K, Funahashi T. Two cases of primary empty sella. Jpn Rev Clin Ophthalmol 1980; 6: 58-62.

8 Nakajyo S, Kiso A, Fujino H, et al. Visual impairment after chiasmapexy for primary empty sella syndrome with descent of the 3rd ventricle. Jpn Rev Clin Ophthalmol 1978; 5: 39-42.

9 Shinoda Y, Nakayoshi N, Matsuo M, et al. Empty sella syndromes with visual field disturbance. Folia Ophthalmol Jpn 1982; 33: $1811-5$.

10 Jordan RM, Kendall JW, Kerber CW. The primary empty sella syndrome. Am J Med 1977; 62: 569-79.

11 Bergrand RM, Ray BS, Trak RM. Anatomical variations in the pituitary gland and adjacent structures in 225 human autopsy cases. J Neurosurg 1977; 28: 93-9.

12 Wirtschafter JD. Diagnosis of the empty sella with intrathecal metrizamide computed tomography. Surv Ophthalmol 1983; 28: 42-4.

Accepted for publication 17 August 1987. 